\title{
Metal responsive transcription factor 1 (MTF-1) regulates zinc dependent cellular processes at the molecular level
}

\author{
Agata Grzywacz ${ }^{1 凶}$, Joanna Gdula-Argasińska², Bożena Muszyńska³, \\ Małgorzata Tyszka-Czochara², Tadeusz Librowski² and Włodzimierz Opoka'
}

1Department of Inorganic Chemistry, Jagiellonian University Medical College, Faculty of Pharmacy, Kraków, Poland; 2 Department of Radioligands, Jagiellonian University Medical College, Faculty of Pharmacy, Kraków, Poland; 3Department of Pharmaceutical Botany, Jagiellonian University Medical College, Faculty of Pharmacy, Kraków, Poland

Metal responsive transcription factor 1 (MTF-1) is a zinc dependent transcription factor which is involved in the regulation of intracellular signaling pathways. MTF-1 regulates the expression of two streams of genes functioning in metal homeostasis and anti-oxidative response. MTF- 1 acts in the process of binding of toxic metal ions in the cell, due to the activation of the expression of metallothioneins (MTs). Additionally, MTF-1 regulates transcription of genes involved in the sequestration of zinc and its intracellular transport. Disruption of zinc and MT homeostasis has an indispensable influence on the development of several pathological states. Moreover, by increasing MT activity, MTF-1 can effectively protect cells from oxidative and hypoxic stresses. The mechanism of MTF-1 action in cells includes the regulation of the proper immune response through activation/repression of anti- and pro-inflammatory cytokines. MTF-1 function in immune response is related to nuclear factor-KB (NF-KB) activity. Synthesis of insulin is also related to the activity of this transcription factor and zinc balance. Insulin transport also depends on zinc. In pancreatic $\beta$-cells, several types of the zinc transporters are found. Zinc transporters coordinated action is crucial for the synthesis and secretion of insulin. Disturbances in the regulation of signaling pathways connected with MTF-1 function can entail further alterations in zinc intracellular status and this growing imbalance can promote the pathophysiology of degenerative disorders.

Key words: metal responsive-transcription factor 1, cell signaling, inflammation, NF-KB

Received: 23 April, 2015; revised: 16 July, 2015; accepted: 31 July, 2015; available on-line: 03 September, 2015

\section{INTRODUCTION}

Zinc is an essential microelement required for cellular homeostasis and function. It plays important roles in nucleic acid metabolism, cell growth, differentiation, replication and cell survival. Deficiency of this nutrient results to a range of pathological conditions, including growth retardation, impaired function of the immune system, neurological disorders and other health diseases (Hirano et al., 2008; Maremanda et al., 2014; Bonaventura et al., 2015). Therefore, zinc homeostasis in cells is tightly regulated, requiring coordinated import and export (gain and losses), as well as precise sensing of intracellular concentrations. Alterations of zinc homeostasis results in complex implications, including the expression of a great number of housekeeping genes, which may affect serious disorders. Zinc, one of the messenger molecules, interacts with a number of receptors in cellular signaling pathways (Hirano et al., 2008). Zinc finger proteins also act as modulators of gene expression (Molkentin, 2000).

Transcription factors constitute a group of proteins which control target gene expression by inhibition or initiation of transcription in response to specific molecular stimuli. One of these transcription factors, metal regulatory transcription factor 1 (MTF-1), represents an interesting zinc receptor involved in a great number of cell processes. MTF-1 is a pluripotent transcriptional regulator localized in both cytoplasm and nucleus. It is involved in cellular adaptation to various stress conditions, primarily exposure to heavy metals, but also to hypoxia and oxidative stress (Saydam et al., 2001; Rutherford et al., 2004; Lichten et al., 2011; Bonaventura et al., 2015). During stress, MTF-1 accumulates in the nucleus, binds DNA, recruits different co-activators and often relies on other transcription factors for a coordinated target gene expression. Since MTF-1 shows increased DNA-binding upon $\mathrm{Zn}$ supplementation, this $\mathrm{Zn}$ finger domain has been suggested to mediate the intrinsic $\mathrm{Zn}$ sensing of MTF-1 (Rutherford et al., 2004; Li et al., 2006; Bonavertura et al., 2015). In this way, transcription factors work to control the development, as well as to maintain the homeostasis and metabolism of the adult organism. Through the regulation of the corresponding genes, MTF-1 influences zinc, iron and copper homeostasis. This transcription factor is involved in the regulation of inflammation, especially activation of pro- or anti-inflammatory cytokines (Mocchegiani et al., 2007). MTF-1 also is involved in the regulation of Ins 1 and Ins 2 genes, which encode insulin and, therefore, it is indispensable in the regulation of glucose homeostasis in organisms (Huang et al., 2010). The precision of these regulatory processes is crucial for proper cell function and may have an influence on the homeostasis of the whole human organism (Kimura \& Itoh, 2008).

\section{MTF-1 AS A TRANSCRIPTION FACTOR}

Zinc-dependent nuclear receptor MTF-1 is a $72.5 \mathrm{kDa}$ protein. MTF-1 has a domain structure typical for intracellular transcription factors, in which various function-

$\triangle$ e-mail: grzywacz.aa@gmail.com

Abbreviations: MT, metallothioneins; MTF-1, metal responsive transcription factor 1; MRE, metal response element, ZnT, zinc transporters 
A)

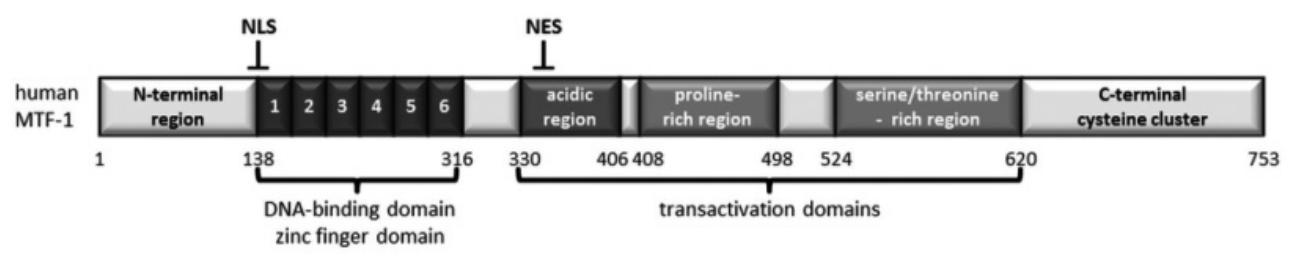

B)
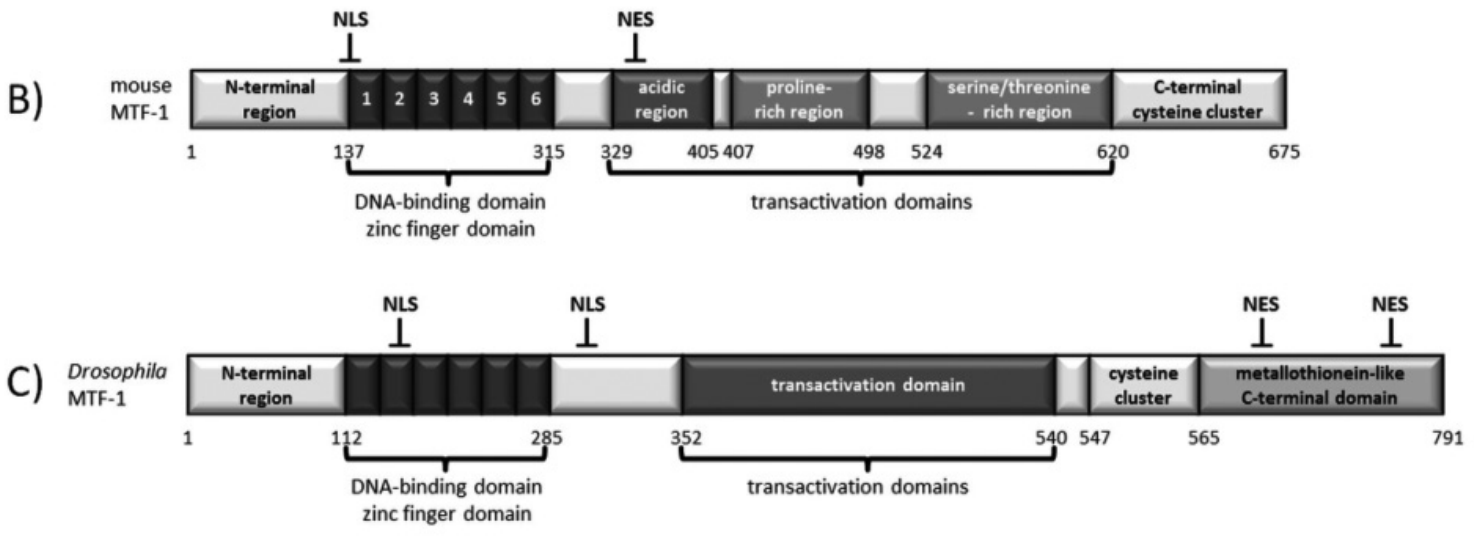

Figure 1. The scheme of MTF-1 with its functional domains.

(A) human; (B) mouse; (C) Drosophila MTF-1 scheme. NLS, nuclear localization signal; NES, nuclear export signal (Günther et al., 2012b).

ing parts can be distinguished. One important functional part is the DNA-binding domain (DBD), which allows detection and binding of the protein to the gene promoter sequence. Other parts may contain several signalsensing domains (SSD) and trans-activation domains (TAD) which detect chemical signals and allow up- or down-regulation of gene expression enabling in this way specific cell response. Like most transcription factors, MTF-1 also has a zinc finger domain including 6 zinc finger structures of $\mathrm{Cys}_{2} \mathrm{His}_{2}$ type, which allows it to conduct interactions with nuclear acids (Giedroc et al., 2001; Bonaventura et al., 2015) (see Fig. 1).

MTF-1 is a conservative protein commonly occurring in eukaryotic cells. It is present in plants, insects and animals. It has also been widely demonstrated that processes regulated by this transcription factor are of great similarity across species. However, data obtained in animal models should be circumspectly interpreted in humans with the awareness of possible differences in MTF-1 structure and function. Several research results have revealed that the MTF-1 protein is shortened in rodents, which might lead to lowered affinity to zinc; otherwise, human MTF-1 response to zinc stimulation is much stronger than that described for rats and mice (Lindert et al., 2008). On the other hand, in insects, for example Drosophila, MTF-1 is well characterized and is responsible for regulation of copper homeostasis (Günther et al., 2012b).

Due to the importance of transcriptional processes for organism survival, multiple layers of regulation and control exist. In the case of MTF-1 and processes connected with its activity, the metal zinc seems to be the crucial messenger and a central factor for crossing physiological pathways; also, MTF-1 needs zinc ions to initiate its activity as a transcription factor. The specific mechanism of zinc sensing by MTF-1 was discussed in detail by $\mathrm{Li}$ and coworkers (2006).

The well-described mechanism of MTF-1 cell stimulation occurs via free zinc ions. Activation of MTF-1 can be proceeded (i) directly by zinc ions in the cytoplasm, (ii) indirectly by liberation of zinc from metallothioneins or (iii) indirectly by phosphorylation/dephosphorylation of the protein (see Fig. 2) (Saydam et al., 2001; Kimura et al., 2009). However, MTF-1 could be stimulated by free intercellular zinc ions (Ruttkay-Nedecky et al., 2013). Activated transcription factors can be transported into the nucleus in a process dependent on interaction with the receptor protein in the nuclear membrane, exportin 1 (Xpo1), which is an importin $\beta$ protein (Lindert et al., 2009). Inside the nucleus, MTF-1 recognizes the specific region of the gene's promoter, the metal-response element (MRE), and then interacts with it. This specific sequence can be found in multiple copies in various genes promoters (Westin and Schaffner 1988). The strength of binding depends on the MTF-1's zinc finger saturation level. Fully zinc-saturated transcription factor can effectively modulate the transcription of genes. Binding of the transcription factor to DNA may either block or induce the formation of the whole transcription protein complex. MTF-1 usually acts as a gene expression inducer, but the repressor effect of MTF-1 has also been reported (Li et al., 2006; Günther et al., 2012a).

Regulation of the transcription processes via MTF-1 may occur during activation of the protein, transport to the nucleus, DNA binding and mRNA processing. Thus, various factors present in the cell may have an influence on transcription factor activity, depending on the cell type, the intensity of the metabolic transitions, the growth of cell, cell cycle regulation, exogenous signals and the environmental context (Kaler and Prasad 2006). It has been reported that MTF-1 interacts with other transcription factors such as nuclear factor 1 (NF-1), CCAAT/enhancer-binding protein alpha $(\mathrm{C} / \mathrm{EBP} \alpha)$, upstream stimulatory factor 1 (USF1) and others (Andrews et al., 2001; Jennings et al., 2013; Lu et al., 2015). The effects of these interactions may be the up-regulation or down-regulation of genes encoding specific classes of MTs (Jackson et al., 2008; Kimura \& Itoh, 2008). 


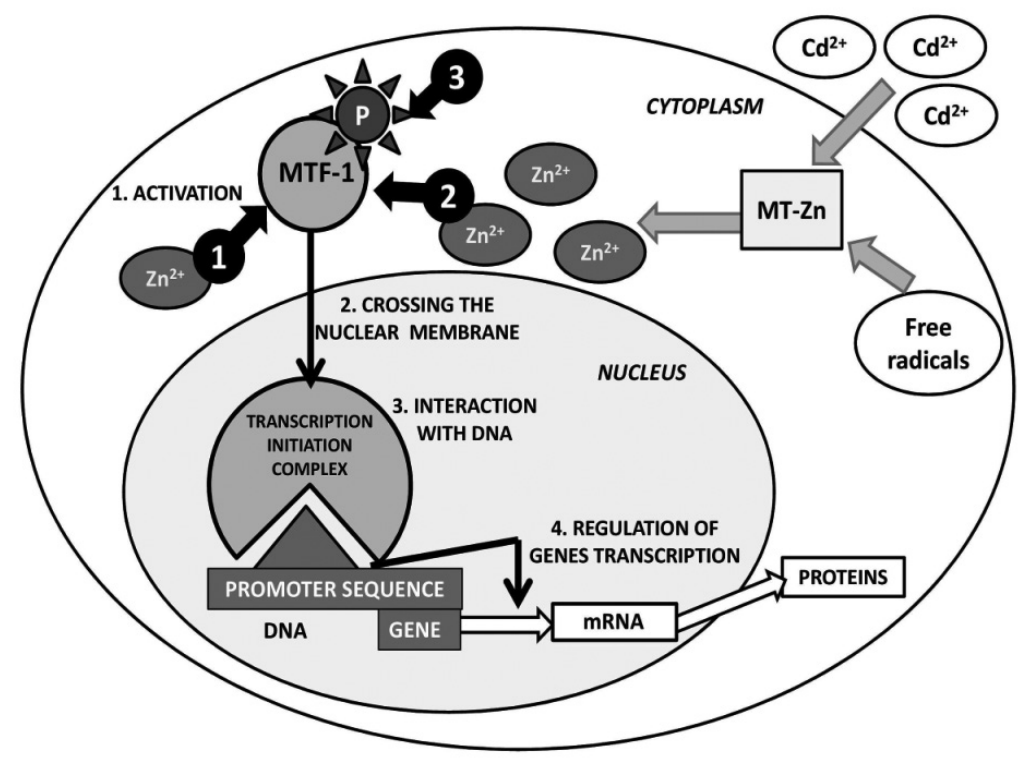

Figure 2. Regulation of the transcription processes via MTF-1.

MTF-1 is essential not only for proper functioning of adult organisms, but it is of vital importance for the development processes (Wang et al., 2004; Maywald \& Rink, 2015). In MTF-1 knock-out mice, the lack of a functional MTF-1 gene is lethal during early embryonic state due to the failed liver development. Therefore, it was concluded that proper liver development depends on the MTF-1 function. The lethal effect observed in knock-out population was probably connected with affected expression of MTF-1 target genes, $\alpha$-fetoprotein $(\mathrm{AFP})$ and $(\mathrm{C} / \mathrm{EBP} \alpha)$; however, the exact mechanism of this process is still unknown. Nevertheless, it was demonstrated that in experimental knock-out mouse liver cells the reintroduction of cDNA for MTF-1 protein caused restoration of cell viability and enabled further cell proliferation in culture. Additionally, knock-out embryos exhibited lowered levels of leukocytes, which suggests that MTF-1 may also be involved in embryonic hematopoiesis (Wang et al., 2004).

Connections between zinc and MTF-1 are well established; much less is understand about MTF-1 influence on other nutrients. Research evidence suggests that MTF-1 may exert an effect on absorption of other metals besides zinc. MTF-1 regulates the target gene for ferroportin 1, the protein which exports iron outside the cell and which is mostly active in cells involved in iron storage. It was demonstrated that induction of this gene expression by MTF-1 supports the connection between iron homeostasis and the available level of zinc ions in organisms. The proposed relationship between both metals is based on possible additional ferroportin 1 transporter activity, which could be zinc export outside a cell, in this way it may influence the cellular level of this ion. However, the molecular basis of that connection is still under intensive investigation (Rutherford et al., 2004). MTF-1 can also exert an effect on copper homeostasis, which may also have adverse implications in the pathogenesis of the central nervous system. Thus, several zinc transporters, especially from the Zip family, i.e. Zip-1 and Zip-2, were suggested to show low copper transport activity. Additionally, in the brain MTF-1 was shown to regulate the transcription of genes encoding prion proteins $(\operatorname{Pr} \mathrm{P})$, which in turn regulate homeostasis of copper by binding the excess of these ions (Bellingham et al., 2009).

Another research study demonstrated that MTF-1 in the brain can be involved in stimulation of $\beta$-synuclein expression. The synuclein proteins in physiological state are involved in the regulation of the phenomena of neuronal plasticity. It was proposed that $\alpha$-synuclein and $\beta$-synuclein interact with each other. However, it has been noticed that the pathology in $\beta$-synuclein function may occur when this protein accumulates in neurofibrillary lesions. This has been observed in patients with several neurodegenerative disorders. Increased expression of $\beta$-synuclein protein may be a result of disturbed MTF-1 regulation, which in turn can contribute to the development of diseases such as Parkinson's disease and Alzheimer's disease (McHugh et al., 2011).

\section{MTF-1 REGULATES ZINC HOMEOSTASIS IN THE CELL VIA SPECIFIC TRANSPORTERS AND METALLOTHIONEINS}

Keeping stable zinc levels in cells is essential to sustain the proper functions of cells and whole organism homeostasis of trace elements. In most mammalian cells, there are two zinc pools (Zalewski et al., 2006). The first one is zinc tightly bound to proteins, i.e. enzymes, the other one is labile zinc, which can easily react with the number of regulatory factors in the cell cytoplasm. The next pool is tissue specific and consists of zinc ions accumulated in vesicles involved in signaling and secretory processes, i.e. in specialized neurons or pancreatic $\beta$-cells (Sekler et al., 2007). The transport of zinc into and outside the mammalian cells is carried out by two families of specific zinc transporters: Zip and ZnT. Zip transporters carry zinc into the cell and $\mathrm{ZnT}$ transporters reduce the zinc levels by ion efflux from cytoplasm to organelles and out of the cell (Laity \& Andrews, 2007; Sekler et al., 2007). Zinc from dietary sources is absorbed in the gastrointestinal tract by active transport, mostly via Zip-4 transporters. In turn, the most abundant zinc exporter localized in the cell membranes, which can reduce zinc levels in the cell, is zinc transporter 1 (ZnT1). Another significant role in zinc transport is performed 
by metallothioneins, which transmit zinc signals inside cells (Lichten \& Cousins, 2009).

MTF-1 stimulates the expression of metallothioneins and ZnT-1 genes and both proteins are indispensable for zinc supply and intracellular sequestration. There are four main isoforms of MTs expressed in humans, where MTs of type 1-2 are ubiquitous and types 3-4 are tissue specific. The cytoplasmic M'Ts are a well-known group of proteins, which have the ability to effectively bind heavy metal ions (i.e. zinc, copper, chromium, cadmium, mercury) (Coyle et al., 2002; Günther et al., 2012a, 2012b). Therefore, these cysteine-rich proteins play a significant role in cell protection against excessive amounts of metal ions and act against oxidative stress, thus constituting the main system of detoxification against toxic heavy metals (Andrews, 2000).

The regulation of the MT genes transcription occurs as a result of physiological processes and the amount of these proteins involved in the regulation of the proper concentration of zinc in the cell. When the amount of zinc increases, the activation of MTF-1 leads to induction of synthesis of MT proteins, which can finally bind the excess of zinc ions. In pathological states, such as heavy metal intoxication, metallothioneins may release zinc ions and bind other toxic elements instead (Günther et al., 2012b). Similarly, oxidative stress causes zinc liberation from MTs. The amount of zinc ions released in this process can be high and could even reach a micromolar concentration. In that case, MTF1 also up-regulates transcription of MT genes until the cell tackles the high zinc levels. As mentioned, high levels of the zinc efflux transporter ZnT-1 in cellular membranes allow intense efflux of excess zinc from the cell and thereby diminish zinc toxicity in the cytosol. So, the induction of the expression of the ZnT-1 is another mechanism which effectively acts against elevated zinc levels. Finally, the zinc concentration in the cell is reduced and, with the decrease in MTF-1 activation, the expression of ZnT-1 genes drops. This molecular mechanism enables the optimum zinc level inside cells to be maintained (Sekler et al., 2007).

\section{MTF-1 ROLE IN DEFENSE AGAINST OXIDATIVE AND HYPOXIC STRESS}

MTF-1 is involved in the defense against oxidative and hypoxic stress in the organism. This transcription factor is very sensitive to the fluctuations in redox cell status and, after stimulation, it promotes the expression of the target genes, mainly several classes of MTs, and this is a zinc dependent process. Additionally, in oxidative stress conditions, MTF-1 activates the expression of the Selenoprotein 1 (Sepw1) gene, which encodes an antioxidant glutathione-binding protein which scavenges free radicals (Bonaventura et al., 2015). Thus, MTF-1 may probably play a protective role against cancer: firstly, by neutralization of oxidative stress; and secondly, by diminishing heavy metal toxicity (Andrews 2000; Stoytcheva et al., 2010). The other antitumor mechanism of MTF-1 action involves a tumor suppressor protein, phosphatase and tensin homolog (PTEN). In this process, PTEN interacts with MTF-1 in the cytoplasm and phosphorylates this transcription factor. Then, MTF-1 activated in such way may be transported to the nucleus, where it exerts an effect on the transcription of genes, such as MTF-1 dependent MTs contributing to cell defense system (Lin et al., 2012).

On the other hand, MTF-1 may protect against the hypoxic stress which occurs when the level of oxygen in the organism and cells is low. In the state of hypoxic stress, MTF-1 can act a central role in cell protection due to its activity in the regulation of hypoxia-inducible factor-1 (HIF-1), which is shown in Fig. 3 (Murphy et al., 2008; Günther et al., 2012a). HIF-1 is the main transcriptional regulator sensitive to hypoxia in mammals, which regulates physiological and pathophysiological responses to oxygen deficiency. Results of recent experiments on the Mtf-1 null mouse embryonic fibroblast model have suggested the existence of complex molecular crosstalk between both MTF-1 and HIF-1 transcription factors. Firstly, MTF-1 is essential for HIF-1 transcriptional activity. It was shown that the expression of well-established HIF-1 target genes, glucose transporter 1 (Glut1) and erythropoietin (Epo), during hypoxia depends on the activity of MTF-1. Secondly, the loss of Mtf-1 genes in the model demonstrated that MTF-1 may have an influence on the nuclear accumulation of $\mathrm{HIF}-1 \alpha$ protein. In the experimental cell line, the level of glutathione (GSH) was elevated in comparison to the control. As a result, the cellular redox state was disturbed, which probably caused the reduction in HIF- $1 \alpha$ accumulation (Murphy et al., 2008). Additionally, another experiment showed that during hypoxia the expression of mouse MT-1 with MTF-1 requires the presence of $\mathrm{HIF}-1 \alpha$ protein subu-

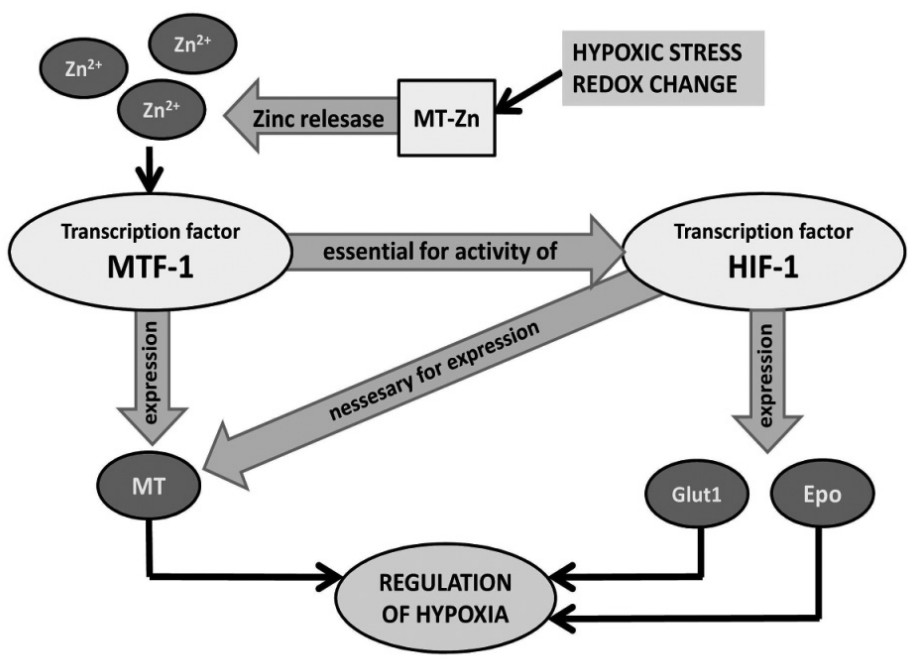

Figure 3. MTF-1 activation has a protective effect against hypoxic stress. 
nits, which have the ability to bind with the regulatory sequence of MT gene promoters. Also, in hypoxic state and the experimentally induced absence of HIF-1 $\alpha$, the expression of MT-1 was unsuccessful, regardless of the zinc (Murphy et al., 2008; Günther et al., 2012a).

Hence, it can be concluded that MTF-1 activity is indispensable for successful defense against stress caused by disturbed oxygen levels in the cell.

\section{MTF-1 REGULATES THE INFLAMMATION PROCESSES VIA CROSSTALK WITH NF-KB}

In the regulation of cell functioning, one transcription factor may exert influence on several signal pathways. Therefore, a detailed analysis of existing crosstalk between these pathways provided by transcription factors can give an insight into the potential response of the particular cell to its environmental stimuli (Kimura et al., 2008; Günther et al., 2012a). It has been demonstrated that in immune response there is a regulatory crosstalk between MTF-1, MTs and corresponding zinc levels and pro-inflammatory cytokines (Kimura et al., 2009; Bonaventura et al., 2015). Zinc and MT homeostasis is fundamental for cellular adaptation to various stress conditions. In healthy individuals, the MT level is low and zinc concentration is sufficient to saturate the MT pool. When an inflammation occurs and redox conditions in a cell change, then zinc ions are released from MTs (Günther et al., 2012a,b). Free zinc ions can upregulate the expression of MTs and other antioxidant proteins, stimulate MTF-1 function and also downregulate the genes of the pro-inflammatory cytokines such as interleukin 6 (IL- 6 ), tumor necrosis factor $\alpha(\mathrm{TNF}-\alpha)$ and interleukin 1 (IL-1). Also, expression of the zinc efflux transporter ZnT-1 gene is upregulated, which in turn helps re-establish the zinc-MT balance and recover the redox status of a cell (Mocchegiani et al., 2007; Bonaventura et al., 2015). On the other hand, there is also a crosstalk between zinc metabolism and interleukin activity, where the induction of MTF-1 by IL-6 occurs through dramatic changes in the concentration of MTs (Li et al., 2006; Kimura et al., 2009).

Additionally, MTF-1 function in immune response is related to nuclear factor $-x \mathrm{~B}(\mathrm{NF}-x \mathrm{~B})$ activity. NF- $x \mathrm{~B}$ can be activated by zinc released from MTs and zinc-de- pendent redox state changes can influence NF- $x \mathrm{~B}$ ability towards DNA binding. This transcription factor's role is to transmit the signals from pro-inflammatory cytokines to the nucleus and regulate the expression of several proteins involved in the inflammation process. During the progress of the inflammation process, NF- $x \mathrm{~B}$ induces the expression of pro-inflammatory cytokines, IL-6 and TNF- $\alpha$ (Cieślak et al., 2015). Moreover, NF- $x$ B may exert a direct effect on the activity of MTF-1 (Kimura et al., 2009; Mocchegiani et al., 2007; Maywald \& Rink, 2015).

Moreover, zinc transporters may play a crucial role in the regulation of immune response (Bonaventura et al., 2015; Maywald \& Rink, 2015). Research conducted on human monocytes, macrophages and lung epithelial cell line models has shown that suppression of Zip-8 expression results in increased production of pro-inflammatory cytokines. On the other hand, over-expression of Zip8 inhibits $\mathrm{NF}-x \mathrm{~B}$ activation induced by $\mathrm{TNF} \alpha$ or IL-1 $\beta$. It is also known that an experimentally increased labile zinc pool can suppress $\mathrm{NF}-\varkappa \mathrm{B}$ signaling and expression of NF- $x \mathrm{~B}$ dependent genes. Therefore, zinc transporter Zip-8 probably acts by delivering zinc into specific places in the cytosol, where it can inhibit IKK kinase, which allows zinc signal response to inflammation. This zinc pool can also effectively increase the level of MTs and activates the MTF-1 transcription factor (Liu et al., 2013).

The crosstalk between MTF-1, zinc and NF- $x \mathrm{~B}$ in inflammatory states is summarized in Fig. 4. In conclusion, transcriptional factor $\mathrm{NF}-\varkappa \mathrm{B}$ is probably the center of the regulation between zinc, MTs and inflammatory cytokines. It is now widely appreciated that chronic lowgrade inflammation plays a key role in the initiation, propagation, and development of metabolic diseases. Consistent with its central role in coordinating inflammatory responses, numerous recent studies have implicated transcription factor $\mathrm{NF}-x \mathrm{~B}$ in the development of such diseases, thereby further establishing inflammation as a critical factor in their etiology and in the development of new therapeutic approaches (Baker et al., 2011).

\section{MTF-1 ROLE IN INSULIN SYNTHESIS}

Increasing evidence from human and laboratory studies shows the effect of zinc on diabetic complications

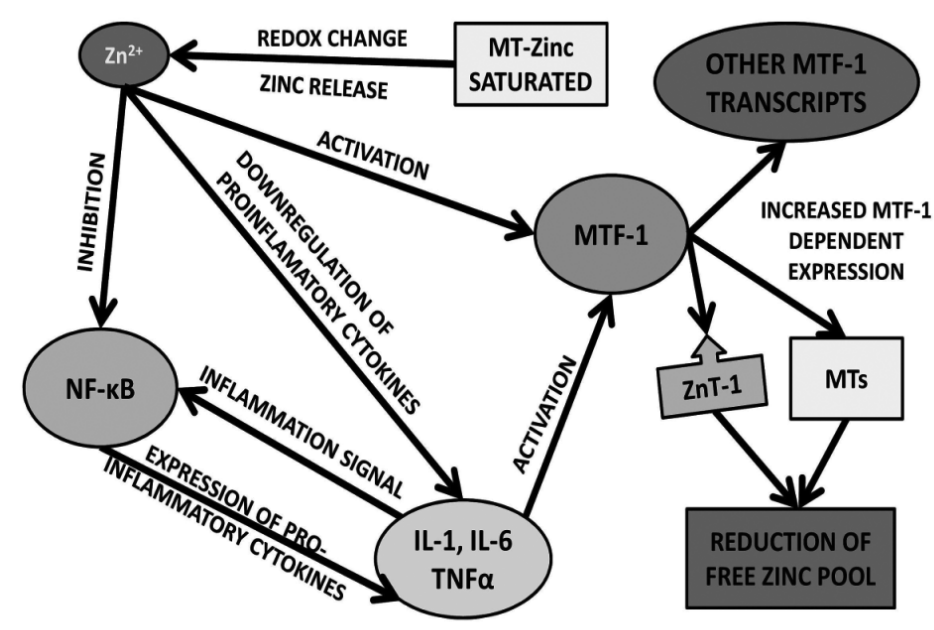

Figure 4. Crosstalk between MTF-1, MTs, Zn and cytokines. 
(Li et al., 2014). It is known that impaired zinc status is connected with pathogenesis of diabetes mellitus of both type 1 and type 2 (Centers for Disease Control and Prevention, 2014). It has been demonstrated several times that zinc ions play an important role in insulin maturation, storage and secretion in pancreatic $\beta$-cells (Emdin et al., 1980; Huang et al., 2010; Kelleher et al., 2011). Accordingly, these cells contain the highest concentration of zinc in organisms, which may reach mmol levels. The function of these cells is to maintain precise amounts of insulin in the bloodstream. In this zinc-dependent process of insulin biosynthesis, harmonized activity of zinc transporters is necessary. Thus, zinc import into the cell is carried out by the Zip-4 zinc transporter. Synthetized proinsulin is transported to the Golgi apparatus granules and secretory vesicles, which contain high amounts of zinc ions. The influx of zinc into insulin vesicles is most likely to occur via $\mathrm{ZnT}-5$ and $\mathrm{ZnT}$-7 zinc transporters, which are involved in zinc accumulation (Emdin et al., 1980; Huang et al., 2010). In pancreatic $\beta$-cells, ZnT8 zinc transporter is also found; however, its function is under intense investigation. Probably, Zn'T-8 plays a role in providing zinc for proper insulin crystallization processing, but some evidence has suggested that this is not essential for maintaining pancreatic function in glucose regulation. However, it has been shown that genetic polymorphism in the ZnT-8 gene is connected with increased risk of type 2 diabetes development (Kelleher et al., 2011).

Accordingly, in rat insulinoma cell lines over-expression of the ZnT-7 zinc transporter gene has been shown to stimulate expression of MT1, ZnT-1 and insulin genes. All these genes are known to be regulated by zinc level and MTF-1 transcription factor (Chimienti, 2013). In this experiment, the total level of produced insulin was two-fold higher, because of stimulated expression, which is due to elevated activity of MTF-1. These findings suggested that in the tested cell model local concentrations of labile zinc ions have to be increased, which is reflected in stimulated expression of zinc efflux transporter ZnT-1 and MT genes. In contrast, total zinc in $\mathrm{ZnT}$-7 overexpressing pancreatic $\beta$-cells lines did not differ from that in the control, in contrast to the $\mathrm{ZnT}-8$ overexpressing model. These findings showed that ZnT7 is involved in the regulation of the insulin biosynthesis pathway, which is also zinc and MTF-1 dependent (Huang et al., 2010). In another study by the same authors, it was demonstrated by electrophoretic mobility shift assay experimentation that the metal responsive element (MRE) in an insulin gene promoter can bind with MTF-1 transcription factor. These findings are also important in the context that all known mammalian insulin genes are most probably regulated by MRE sequences in the promoter section (Huang et al., 2010).

In the pathogenesis of diabetes mellitus, disturbance in the proper function and signaling in pancreatic $\beta$-cells has often been observed, which in consequence leads to a decrease in the synthesis and secretion of insulin. Clinical studies have shown correlations between zinc homeostasis disruption and altered, typically lowered, serum zinc levels in diabetic and pre-diabetic patients. There is also growing evidence concerning promising results of zinc supplementation in diabetes treatment (Anderson et al., 2001; Chimienti, 2013).

It can be concluded that molecular crosstalk between zinc transporters, metallothioneins and transcription factors, i.e. MTF-1, in the functioning of $\beta$-cells (Fig. 5) may play a significant role in the pathogenesis and progress of diabetic states.

\section{CONCLUSIONS}

The function of MTF-1 is multithreaded and it occurs via the crosstalk between molecules that comprise biochemical processes and signaling pathways in the cell. The proper regulation through transcription factors allows an organism to dynamically follow up changes in environmental conditions and to undertake a proper reaction in order to sustain whole body homeostasis. By controlling the expression of MTs, MTF-1 is involved in the homeostasis and balance of trace elements (zinc, iron, copper) and thus enables the proper response of the cell to physiological and toxic stimuli. Additionally, MTF-1 regulates the transcription of genes crucial for the proper function of organisms at all development

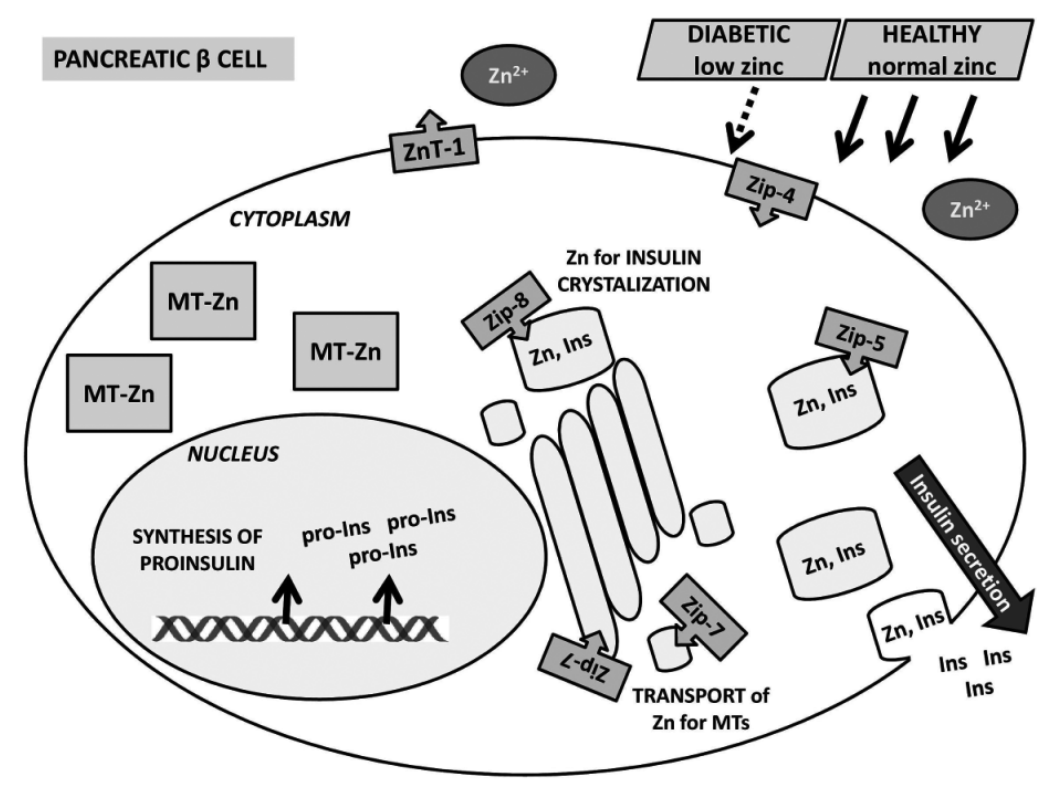

Figure 5. Zinc and MTF-1 dependent regulation of insulin biosynthesis pathway. 
stages. MTF-1 regulates a number of crucial processes and essential functions of the cell. Control over the transcription of MTF-1 target genes is important for the prevention of the development of pathological states. MTF-1 constitutes a promising target in the search for new drugs and for the control of drug side effects. On the other hand, its influence on signal pathways is very complex and it should be noted that intervention via MTF-1 may lead to surprising effects.

\section{REFERENCES}

Anderson RA, Roussel AM, Zouari N, Mahjoub S, Matheau JM, Kerkeni A (2001) Potential Antioxidant Effects Of Zinc And Chromium Supplementation In People With Type 2 Diabetes Mellitus. J Am Coll Nutr 20: 212-218. http://dx.doi.org/10.1080/07315724.2001.1 0719034.

Andrews GK, Lee DK, Ravindra R, Lichtlen P, Sirito M, Sawadogo M, Schaffner W (2001) The Transcription Factors Mtf-1 and Usf1 cooperate to regulate mouse metallothionein-1 expression in response to the essential metal zinc in visceral endoderm cells during early development. Embo J 20: 1114-1122. http://dx.doi.org/10.1093/ emboj/20.5.1114.

Andrews GK (2000) Regulation of metallothionein gene expression by oxidative stress and metal ions. Biochem Pharmacol 59: 95-104. http://dx.doi.org/10.1016/S0006-2952(99)00301-9.

Baker RG, Hayden MS, Ghosh S (2011) NF-xB, Inflammation, and metabolic disease. Cell Metab 13: 11-22. http://dx.doi.org/10.1016/j. cmet.2010.12.008.

Bellingham SA, Coleman LA, Masters CL, Camakaris J, Hill AF (2009) Regulation of prion gene expression by transcription factors Sp1 and metal transcription factor-1. J Biol Chem 284: 1291-1301. http://dx.doi.org/10.1074/jbc.M804755200.

Bonaventura P, Benedetti G, Albarède F, Miossec P (2015) Zinc and its role in immunity and inflammation. Autoimmunity Rev 14: $277-$ 285. http://dx.doi.org/10.1016/j.autrev.2014.11.008.

Chimienti F (2013) Zinc, pancreatic islet cell function and diabetes: new insights into an old story. Nutr Res Rev 26: 1-11. http://dx.doi. org/10.1017/S0954422412000212.

Cieślak M, Wojtczak A, Cieślak M (2015) Role of pro- inflammatory cytokines of pancreatic islets and prospects of elaboration of new methods for the diabetes treatment. Acta Biochim Pol 62: 15-21. http://dx.doi.org/10.18388/abp.2014853.

Coyle P, Philcox JC, Carey LC, Rofe AM (2002) Methallothionein: The Multipurpose Protein Cell Mol Life Sci 59: 627-647. http://dx.doi. org/10.1007/s00018-002-8454-2.

Emdin SO, Dodson GG, Cutfield JM, Cutfield SM (1980) Role of zinc in insulin biosynthesis. some possible zinc-insulin interactions in the pancreatic $\beta$-cell. Diabetologia 19: 174-182. http://dx.doi. org/10.1007/BF00275265.

Giedroc DP, Chen X, Apuy JL (2001) Metal Response Element (MRE)-Binding Transcription Factor-1 (Mtf-1): Structure, Function, And Regulation. Antioxid Redox Signal 3: 577-596. doi:10.1089/15230860152542943.

Günther V, Davis AL, Georgiev O, Schaffner W (2012a) A conserved cysteine cluster, essential for transcriptional activity, mediates homodimerization of human metal-responsive transcription factor-1 (MTF-1) Biochim Biophys Acta 1823: 476-483 http://dx.doi. org/10.1016/j.bbamcr.2011.10.006.

Günther V, Lindert U, Schaffner W (2012b) The taste of heavy metals: Gene regulation by MTF-1. Biochim Biophys Acta 1823: 1416-1425. http://dx.doi.org/10.1016/j.bbamcr.2012.01.005.

Hirano T, Murakami M, Fukada T, Nishida K, Yamasaki S, Suzuki T (2008) Roles of zinc and zinc signalling in immunity: zinc as an intracellular signalling molecule. Adv Immunol 97: 149-76. http://dx. doi.org/10.1016/S0065-2776(08)00003-5.

Huang L, Yan M, Kirschke CP (2010) Over-expression of Znt7 increases insulin synthesis and secretion in pancreatic beta-cells by promoting insulin gene transcription. Exp Cell Res 316: 2630-2643. http://dx.doi.org/10.1016/j.yexcr.2010.06.017.

Jackson KA, Valentine RA, Coneyworth LJ, Mathers JC, Ford D (2008) Mechanisms of mammalian zinc-regulated gene expression. Biochem Soc Trans 36: 1262-1266. http://dx.doi.org/10.1042/ BST0361262.

Jennings P, Limonciel A, Felice L, Leonard MO (2013) An overview of transcriptional regulation in response to toxicological insult. Arch Toxicol 87: 49-72 http://dx.doi.org/10.1007/s00204-012-0919-y.

Kaler P, Prasad R (2006) Molecular cloning and functional characterization of novel zinc transporter zip10 (Slc39a10) involved in zinc uptake across rat renal brush-border membrane. Am J Physiol Renal Physiol 292: 217-229. DOI:10.1152/ajprenal.00014.2006.
Kelleher SL, Mc Cormick NH, Velasquez V, Lopez V (2011) Zinc in specialized secretory tissues: roles in the pancreas, prostate, and mammary gland. Adv Nutr 2: 101-11. http://dx.doi.org/10.3945/ an. 110.000232 .

Kimura T, Itoh N (2008) Function of metallothionein in gene expression and signal transduction: newly found protective role of metellothionein. J Health Science 54: 251-260. http://dx.doi.org/10.1248/ jhs.54.251.

Kimura T, Okamura F, Oguro I, Nakanishi T, Sone T, Isobe M et al., (2009) Metal Response Element-Binding Transcription Factor-1 is activated by degradation of metallothionein. J Health Sci 55: 72-76. http://dx.doi.org/10.1248/jhs.55.72.

Laity JH and Andrews GK (2007) Understanding the mechanisms of zinc-sensing by metal-response element binding transcription factor-1 (MTF-1). Arch Biochem Biophys 463: 201-210. http://dx.doi. org/10.1016/j.abb.2007.03.019.

Li B, Cui W, Tan Y, Luo P, Chen Q, Zhang C, Qu W, Miao L, Cai $\mathrm{L}$ (2014) Zinc is essential for the transcription function of $\mathrm{Nrf2}$ inhuman renal tubule cells in vitro and mouse kidney in vivo under the diabetic condition. J Cell Mol Med 18: 895-906. http://dx.doi. org/10.1111/jcmm.12239.

Li Y, Kimura T, Laity JH, Andrews GK (2006) The zinc-sensing mechanism of mouse Mtf-1 involves linker peptides between the zinc fingers. Mol Cell Biol 26: 5580-5587. http://dx.doi.org/10.1128/ MCB.00471-06.

Lichten LA, Cousins RJ (2009) Mammalian Zinc Transporters: nutritional and physiologic regulation. Annu Rev Nutr 29: 153-176. http://dx.doi.org/10.1146/annurev-nutr-033009-083312.

Lichten LA, Ryu M-S, Guo L, Embury J, Cousins RJ (2011). MTF-1-mediated repression of the zinc transporter Zip10 is alleviated by zinc restriction. PloS One 6: e21526. http://dx.doi. org/10.1371/journal.pone.0021526.

Lin MC, Liu YC, Tam MF, Lu YJ, Hsieh YT, Lin LY (2012) PTEN interacts with Metal-Responsive Transcription Factor 1 and stimulates its transcriptional activity. Biochem J 441: 367-377. http://dx. doi.org/10.1042/BJ20111257.

Lindert U, Cramer M, Meuli M, Georgiev O, Schaffner W (2009) Metal-Responsive Transcription Factor 1 (Mtf-1) activity is regulated by a nonconventional nuclear localization signal and a metal-responsive transactivation domain. Mol Cell Biol 29: 6283-6293. http://dx.doi. org/10.1128/MCB.00847-09.

Lindert U, Leuzinger L, Steiner K, Georgiev O, Schaffner W (2008) Characterization of Metal-Responsive Transcription Factor (Mtf-1) from the giant rodent capybara reveals features in common with human as well as with small rodents (mouse, rat). Chem Biodivers 5: 1485-1494. http://dx.doi.org/10.1002/cbdv.200890137.

Liu MJ, Bao S, Galvez-Perlata M, Pyle CJ, Rudawsky AC, Pavlovicz $\mathrm{RE}$ et al. (2013) The zinc transporter Slc39a8 is a negative feedback regulator of NF- $x \mathrm{~B}$ through zinc-mediated inhibition of Ikk. Cell Rep 3: 386-400. http://dx.doi.org/10.1016/j.celrep.2013.01.009.

Lu YJ, Liu YC, Lin MC, Chen YT, Lin LY (2015) Coordinative modulation of human zinc transporter 2 gene expression through active and suppressive regulators. J Nutr Biochem 26: 351-359. http://dx. doi.org/10.1016/j.jnutbio.2014.11.009.

Maremanda KP, Khan S, Jena G (2014) Zinc protects cyclophosphamide-induced testicular damage in rat: Involvement of metallothionein, tesmin and Nrf2. Biochem Biophys Res Commun 445: 591596. http://dx.doi.org/10.1016/j.bbrc.2014.02.055.

Maywald M, Rink L (2015) Zinc homeostasis and immunosenescence. J Trace Elem Med Biol 29: 24-30. http://dx.doi.org/10.1016/j. jtemb.2014.06.003.

Mc Hugh PC, Wright JA, Brown DR (2011) Transcriptional regulation of the beta-synuclein 5'-promoter metal response element by Metal Transcription Factor-1. PloS One 6: e17354. http://dx.doi. org/10.1371/journal.pone.0017354.

Mocchegiani E, Giacconi R, Muti E, Cipriano C, Costarellil, Tesei S, et al., (2007) Zinc-bound metallothioneins and immune plasticity: lessons from very old mice and humans. Imm Ageing 4: 7. http:// dx.doi.org/10.1186/1742-4933-4-7.

Molkentin J (2000) The Zinc Finger-containing Transcription Factors GATA-4, -5, and -6 Ubiquitously Expressed Regulators of TissueSpecific Gene Expression. J Biol Chem 275, 38949-38952. http:// dx.doi.org/10.1074/jbc.R000029200.

Murphy BJ, Kimura T, Sato BG, Shi Y, Andrews GK (2008) Metallothionein induction by hypoxia involves cooperative interactions between Metal-Responsive Transcription Factor-1 and hypoxiainducible Transcription Factor-1alpha. Mol Cancer Res 6: 483-490. http://dx.doi.org/10.1158/1541-7786.MCR-07-0341.

Rutherford JC, Bird AJ (2004) Metal-Responsive Transcription Factors that regulate iron, zinc, and copper homeostasis in eukaryotic cells. Eukaryotic Cell 3: 1-13. http://dx.doi.org/10.1128/EC.3.1.1-13.2004.

Ruttkay-Nedecky B, Nejdl L, Gumulec J, Zitka O, Masarik M, Eckschlager T, Stiborova M, Adam V, Kizek R (2013) The Role of Metallothionein in Oxidative Stress. Int J Mol Sci 14: 6044-6066. http://dx.doi.org/10.3390/ijms14036044. 
Saydam N, Georgiev O, Nakano MY, Greber UF, Schaffner W (2001) Nucleo-cytoplasmic trafficking of Metal-Regulatory Transcription Factor 1 is regulated by diverse stress signals. I Biol Chem 276: 25487-25495. http://dx.doi.org/10.1074/jbc.M009154200.

Sekler I, Sensi SL, Hershfinkel M, Silverman WF (2007) Mechanism and regulation of cellular zinc transport. Mol Med 13: 337-343. http://dx.doi.org/10.2119/2007-00037.Sekler.

Stoytcheva ZR, Vladimirov V, Douet V, Stoychev I, Berry MJ (2010) Metal transcription factor-1 regulation via MREs in the transcribed regions of selenoprotein $\mathrm{H}$ and other metal-responsive genes. Biochim Biophys Acta 1800: 416-424. http://dx.doi.org/10.1016/j.bbagen.2009.11.003.
Wang Y, Wimmer U, Lichtlen P, Inderbitzin D, Stieger B, Meier PJ et al. (2004) Metal-Responsive Transcription Factor-1 (Mtf-1) is essential for embryonic liver development and heavy metal detoxification in the adult liver. Faseb J 18: 1071-1079. http://dx.doi.org/10.1096/ fj. $03-1282 \mathrm{com}$.

Westin G, Schaffner W (1988) A zinc-responsive factor interacts with a metal-regulated enhancer element (MRE) of the mouse metallothionein-I gene. Embo J 7: 3763-3770.

Zalewski P, Truong-Tran A, Lincoln S, Ward D, Shankar A, Coyle P et al. (2006) Use of a zinc fluorophore to measure labile pools of zinc in body fluids and cell-conditioned media. Biotechniques 40: 509-520. http://dx.doi.org/10.2144/06404RR02. 